\title{
Expanding Diversity in STEM: Developing International Education and Re- search Partnerships in a Global Society
}

\section{Dr. Christopher Lum, University of Washington}

Dr. Lum received his $\mathrm{PhD}$ in Aeronautics \& Astronautics from the University of Washington in 2009. He is currently a research scientist at the University of Washington's William E. Boeing Aeronautics \& Astronautics Department and runs the Autonomous Flight Systems Laboratory. His research interests includes coordinated multi-vehicle searching, automatic target recognition, formation flight of swarms of vehicles, risk assessment of UAS in the national airspace, collision avoidance/deconfliction, and UAS flight operations. He has worked closely with industry partners such as the Boeing Company, Insitu, Aerovel, Hood Technology, and the Washington Joint Center for Aerospace Technology Innovation to implement academic technologies onto deployed platforms. Dr. Lum teaches both undergraduate and graduate course on automatic control, flight mechanics, modeling and simulation, mathematical tools for engineers, sensors and actuators, and other controls related courses. He has been awarded the department's "Instructor of the Year" award twice (2012 and 2013). He is also the faculty advisor to the department's design, build, fly team. He has served as an adjunct professor at Seattle University and as a visiting fellow at the Queensland University of Technology in Brisbane, Australia.

\section{Ms. Stephanie Gardner, University of Washington}

Stephanie earned her B.A. in Communications from the University of Washington (UW) in 2001 and her M.Ed. in Educational Leadership and Policy in 2006. She is currently a Doctoral Candidate in the UW College of Education (higher education track) with a research focus on STEM identity development. Most recently she received her certificate of participation from Harvard University's Graduate School of Education, Management Development Program. Over the years Ms. Gardner has advocated extensively on behalf of access, retention, and graduation for underrepresented populations. Many of her professional experiences have been with federal programs including the National Science Foundation (NSF) and Department of Education (DOE). Ms. Gardner has served on a number of committees and has extensive event and public relations experience. As the Assistant Director for the UW Office of Minority Affairs \& Diversity (OMA\&D) Community and Public Relations (CPR) Unit, she provided leadership, strategic direction, and concept development for programs including: the OMA\&D 40-Year Campus Celebration of Diversity, Homecoming Weekend Celebration, Alumni Spring Mixer and served as the Co-Committee Chair for the annual department FEOP Celebration Fundraiser. Additionally, she served as a key leader and member of the UW OMA\&D Outreach and Recruitment Unit that contributed to two consecutive years of increased underrepresented freshmen student enrollment at the UW. In her current capacity as the Director for the Pacific Northwest Louis Stokes Alliance for Minority Participation (LSAMP) Program at the UW, she strives to increase the recruitment, retention and graduation rates for underrepresented students in STEM disciplines while providing experiential and research opportunities. Through the LSAMP Program she was able to co-write the OMA\&D/UW College of Engineering STEM focused study abroad seminar to Brisbane, Australia. This was selected for a best practice model workshop at the 2013 LSAMP National Conference. Her accomplishments include being selected and featured in the 2009 AKA Calendar-"Seattle Up and Coming Young African American Professionals", nominated and selected as a UW Pangaea international staff study abroad participant to Paris, France, serving as the former Chair of the Education and Youth Empowerment Committee for the Seattle Urban League Young Professionals, receiving the OMA\&D Outstanding Contribution Award in 2007, acceptance into the Alene Moris National Education Women's Leadership Institute, selection into the Leadership Tomorrow 2016 cohort, and awarded certification through the College Board Summer Institute on Admissions and School Relations. Currently, Ms. Gardner is a member of the National Association for Student Affairs Administrators (NASPA) in Higher Education and serves on the national board for the African American Knowledge Community (AAKC) as the Conference Social Chair, formerly serving as the Best Practices Spotlight Chair. She has volunteered with the organization as a NASPA Region V Awards Reviewer and 2014 NASPA Western Regional Conference Reviewer. Her most recent project includes serving as a founding board member on the first African American Black Political Action Committee (PAC) in Washington 
State in the capacity of the Membership Coordinator. Ms. Gardner enjoys serving on the Technology Access Foundation (TAF) Board of Directors and as an Advisor to UW Sisterhood.

\section{Ms. Cathryne Jordan, University of Washington}

Cathryne, UW College of Engineering, Assistant Director of Diversity and Access, Director of Women in Science and Engineering (WISE) program. Directing and working with the educational K-20 community, university, public and/or private sector outreach and recruitment programs, she focuses on the recruitment and retention of students pursuing their undergraduate and/or graduate level degree in the STEM disciplines. Focuses on student populations that are traditionally and historically underrepresented within higher education and engineering. Cathryne earned a BA in Speech Communication, Masters in Public Affairs (MPA), and is currently pursuing an Ed.D. in Educational Leadership and Policy Studies.

\section{Dr. Matthew Dunbabin, Queensland University of Technology}

Dr Matthew Dunbabin joined QUT as a Principal Research Fellow (Autonomous Systems) in 2013. He is known internationally for his research into field robotics, particularly environmental robots, and their application to large-scale monitoring. He has wide research interests including adaptive sampling and path planning, vision-based navigation, cooperative robotics, as well as robot and sensor network interactions. Dr Dunbabin received his Bachelor of Engineering in Aerospace Engineering from the Royal Melbourne Institute of Technology and his PhD from the Queensland University of Technology. He started his professional career in 1995 as a project engineer at Roaduser Research International, and following his $\mathrm{PhD}$ joined the Commonwealth Scientific and Industrial Research Organisation (CSIRO) in the Autonomous Systems Laboratory. At CSIRO he held various roles including Principal Research Scientist, project leader and the Robotics Systems and Marine Robotics team leader before moving to QUT in 2013. A strong advocate of robotic systems in civilian applications, Dr Dunbabin is involved in a number of initiatives aimed at promoting, educating and demonstrating autonomous systems to a range of interest groups nationally and internationally. 


\section{Expanding Diversity in STEM: Developing International Education and Research Partnerships in a Global Society}

This paper describes the process of building a successful education and research relationship between the University of Washington (UW) in Seattle, WA, USA and the Queensland University of Technology (QUT) in Brisbane, QLD, Australia with a focus on recruitment of diverse students who traditionally have not participated in study abroad programs. The UW has a gap in terms of underrepresented minorities and/or women engaged in science, technology, engineering, and math (STEM) related study abroad programs as well as STEM majors. International study-abroad programs primarily focus on social science disciplines and there are few opportunities for international studies in STEM fields such as aerospace engineering. The program described in this paper began as an engineering-focused study abroad program operated by the UW with QUT as the host university. At its inception, the goal of the program was to develop a holistic and community based approach for building a program around the student experience with a focus on women and underrepresented students. This involves equal participation from the faculty director, program staff, host university personnel and industry. This program is unique in that it has blossomed to a collaborative research relationship over the course of four years. In addition to conducting annual study abroad programs at QUT, students involved in this program have continued to perform research with their home university while collaborating with the host university. Bi-directional student exchange for research internships and technical publications have materialized from this relationship.

This paper will present the mechanics and logistics associated with conducting an annual, international study abroad program. It will describe the structure of the program as well as comparison to similar programs. The paper will also describe how the relationship grew beyond a course-based program to a collaborative research-based partnership. The associated opportunities, challenges, and risks associated with this growth are presented. Impacts and program significance will be presented in the form of data collected from over 60 program participants over the course of four years.

literature review

Study abroad programs provide unique experiences in new and unfamiliar environments, improve cultural awareness, expanded worldview, and enhance critical thinking and global competence. They offer an opportunity for students to gain diverse academic and life experiences in and out of the academic environment as well as expand employment opportunities for future careers [1]. In addition to providing unique experiences, findings reported by the Georgia Learning Outcomes of Students Studying Abroad Research Initiative (GLOSSARI) show studying abroad has various positive academic benefits. Benefits include but are not limited to 1) higher graduation rates; 2) improved academic performance in the subsequent term; and 3) improvement in academic performance for at-risk students [2]. Within today's global society, American college graduates are lacking crucial international experiences and acquisition of a second language - especially underrepresented minority students. The majority of American students who do not partake in international experiences are identified as: students of color, 
males, lesbian gay bisexual transgendered (LGBTQ); low socio-economic status, first generation, and STEM students [3].

The Institute of International Education's Open Door report data shows the number of students from the United States (U.S.) who study abroad increased by 5\% in 2013/14, the highest rate of growth since before the 2008 economic downturn [4], [5]. While study abroad by undergraduate students (for credit) has more than tripled in the last two decades, rising from 129,770 in 1998/99 to 262,416 in $2007 / 08$ (currently 304,467 in $2012 / 2013$ ) only about $10 \%$ of U.S. students study abroad before graduating from college [6], [4], [5]. Students majoring in STEM fields represent the largest proportion of students studying abroad at nearly $23 \%$, slightly outnumbering Business (20\%) and Social Sciences (19\%) majors. These aforementioned figures are compared to $36 \%$ of all U.S. undergraduates who major in STEM fields, thus STEM students are still underrepresented in study abroad programs. These numbers are even more stagnant for historically underrepresented minority student populations (African American, Hispanic, Pacific Islander/Southeast Asian, and American Indian/Alaska Native). Even more dismal is data from the Institute of International Education and the U.S. Department of Education that shows participation rates have been stagnant for the historically underrepresented student populations for many years. The numbers have been modest - increasing from 16\% in 2003/04 to 26 percent in years 2013/14 [4], [5].

Sociologist and a large body of literature support the understanding that students' educational choices are made within the boundaries of their unique social contexts [1]. Research has shown that students from historically underrepresented populations often face additional obstacles than their majority counterparts as they persist in higher education due to cultural, social and economic constructs constructed prior to college [1]. Disparity in participation rates of minority and or low socioeconomic students is related to the historical development of study abroad programs. Programs were considered a luxury, expensive, usually offered at exclusive institutions with a large if not all-white majority population, which alluded to a perception of limited access for those from social elite and wealthy families. Despite a combination of outreach efforts in higher education and continual improvements in diversity programming, minority and lower socioeconomic status students do not typically participate in and or consider study abroad programs. Studying abroad is still viewed as something restricted to white affluent, upper or middle class students. It is also more associated with class and gender and being more females than males [1], [6]. Data has shown the minorities, students receiving federal aid, and first generations students are less likely to participate in study abroad programs [6]. This can become a hindrance when completing for jobs both stateside and abroad [3]. These populations are underrepresented in study abroad program when compared to their relative populations at their home institutions [1], [7], [8]. Minorities accounted for 37\% of enrollment in higher education and only $18.6 \%$ in study abroad programs [2], [3]. Taking into consideration that more blacks are in higher education than ever before, they only represent about $5 \%$ of the American students studying abroad. This translates into missed opportunities in international careers, leadership positions and reduces society of social capital [9], [10]. Studies and findings suggest that the racial disparities for underrepresented minority students studying abroad are influenced by a combination of many socio accumulated and institutionalized factors. In her 
opening address at the 1990 CIEE Annual Conference, Dr. Johnnetta Cole, then President of Spelman College, identified four major obstacles to African Americans studying abroad. These factors commonly referred to as the "F's" of studying abroad for minority students, especially Black/African American students:

- Faculty and Staff (from failing to encourage black students)

- Finances (black students are more likely to come from families with lower incomes)

- Family and Community (safety issues and concerns about racism in an unknown place)

- Fears (student worries about encountering new forms of racism)

Of all these factors, financing can be one of the major barriers that increase the disparity in studying abroad. Students often rely on financial aid and cannot afford the additional expense of the educational experience abroad. There is a hesitancy to borrow money via loans to fund other co-curricular college experiences such as study abroad. Many students work or participate in internships during the summer and foregoing possible earnings and incurring new expense is hard to fathom. Many universities tend to have additional or separate funding through scholarships and grants but do not adequately or strategically promote these opportunities among their underrepresented students.

The family community and a student's social network raise caution through concerns and ideologies about study abroad, family obligations, pressure to move through college by engaging in the basic required major courses, graduating and quickly entering the workforce, safety issues and concerns about racism abroad. In relation to the institutional faculty/staff factors, concerns about graduating on time and a lack of general information about participating in study abroad were reported to be of greater concern than were concerns regarding family support. The perceived presumptions among faculty and administrators that minorities lack an interest in studying abroad and may be only interested in going to locations that represent their culture; such as Africa for blacks or Spanish speaking countries for Hispanic/Latino students adds to the propensity. Lack of or absence of minority faculty or staff leading a program also contributes to participation rates. Destination choices tend to be in heavily aligned with the European culture. European destinations, in a un-intentioned but biased way, may result in fewer minority students as well [1], [6].

Fear of racism - research suggests that students who are susceptible to stereotype threat (potential interpretations of ones' actions through an existing negative lens) often respond by adjusting behavior patterns to minimize or avoid similar situations [11]. Students of color and more often African American college students at predominantly white institutions are often already vulnerable to such negativism. Since study abroad is rarely required as part of the undergraduate curriculum, they are more likely to decline the opportunity even in the presence of other incentives [11], [6]. Studying abroad is often marketed as a means to improve ones' cross cultural experience. For the minority student in most cases a cross cultural experience is their regular everyday life. It is important to have a more enlightened and diversified vision toward 
creating a more personable, practical and holistic institutional approach to studying abroad for students of color [6].

structure and partnership

In the summer of 2010, a team comprised of student affairs practitioners from the University of Washington (UW) College of Engineering (COE) - Student Academic Services (SAS) -Women in Science and Engineering (WiSE) program and the Office of Minority Affairs \& Diversity (OMA\&D) - Louis Stokes Alliance for Minority Participation (LSAMP) program conducted an environmental scan of the UW campus and discovered there were limited offerings of STEM study abroad programs. There were also small numbers of diverse students who were partaking in international opportunities. As the WiSE and LSAMP program missions were focused on recruitment and retention of diverse populations in the STEM fields, the program administrators determined there was a clear need for a study abroad program that addressed STEM content with a focus on populations who have historically not participated in study abroad opportunities. The salient gaps in international study abroad programming served as a catalyst for the creation of the Australia study abroad program that is a standing partnership among faculty, practitioners, colleges and departments.

The program formally launched in summer of 2011 to Brisbane, Australia in collaboration with QUT. The program structure is unique as many of the current UW study abroad programs are solely led by faculty; however, the Australia program draws upon the strengths of a team-based approach that engages both faculty and student affairs professionals. The program began in 2011 with Dr. Kristi Morgansen-Hill, Professor in the UW COE William E. Boeing Department of Aeronautics \& Astronautics (UWAA), serving as the initial faculty leader. Dr. Morgansen-Hill was able to leverage previous partnerships with industry representatives and faculty on the QUT campus. One of the key QUT faculty being Dr. Ryan Smith. During the first year of the program, these prior relationships were vital in helping program staff connect with key QUT administrators who would be critical to the continuation of the program in future years. Since the initial partnership, the faculty leads have rotated with the current effort being led by Dr. Christopher Lum, Research Assistant Professor in the UW William E. Boeing Department of Aeronautics \& Astronautics and Dr. Matthew Dunbabin, Principal Research Fellow (Autonomous Systems) at the Institute for Future Environments, QUT.

From the initial development stages the team decided to engage students through a holistic approach. This approach includes a series of recruitment, retention and pre and post meetings that address the diverse needs of student participants. Given the historic lower participation rates of those from disadvantaged backgrounds, the program conducts targeted outreach to recruit students from low-socioeconomic backgrounds, first generation status, underrepresented minorities and women who are underrepresented in the field of Engineering. Multiple partners across the UW help facilitate a student's journey including: international partners, industry, private donors, families, the financial aid office, counseling services, scholarship office, International Programs and Exchanges (IPE) office, and university advancement. 
Students are recruited during the early winter months through various social media outlets, email announcements and two information sessions. Alumni of the program serve as the most viable program ambassadors, as they are able to share personal experiences with potential recruits. Once the online application closes students are then selected for interviews. Initial screening of applicants places emphasis on a completed application, short essays, grade point average (GPA), major status and letters of recommendation. During early spring quarter the team conducts two sets of group interviews led by the UW faculty lead, staff, and past participants. Candidates are selected for interviews based on a number of qualifications and attributes, including consideration for major status, diversity, experience in group settings, academic performance, mentor letters, maturity, and first time international traveler status. At the conclusion of the interviews 13-15 students are selected as finalists for the cohort.

One of the goals for the selection of candidates is to pull from a variety of STEM disciplines. The team places a high value on cross mentorship and interdisciplinary engagement amongst participants. Therefore, students represent majors that span the physical to life sciences as well as varying class standing. After students are selected they meet at least three to four times with their cohort for pre-departure meetings. Pre-departure meetings provide an opportunity for students to build community, learn more about the host country, and receive vital information relative to visas, health and wellness, and class expectations. In addition to the pre-departure meetings the cohort has one to two technical meetings with the lead UW faculty member. The technical meetings introduce students to engineering analysis tools that will be required for the class. Historically this has included topics such as software programming using Matlab (the program used for numerical data reduction and analysis), autonomous systems simulators, or professional typesetting software (LaTeX). For students who may be experienced in these topics, these sessions serve as a review and as a chance to identify students who may be able to serve as technical mentors to less experienced participants. Between the pre-departure meetings and actual departure date students receive ongoing reminders about deadlines and program announcements. Because many of the students are low income, come from underserved communities, or have little to no international travel the program staff works with students and their families to talk through the financial aid process, registration, and address any concerns about the program. The staff also partner with departments to secure donations, scholarships and assist with fundraising.

The actual execution of the class is a one-month intensive immersion. Students live in apartment style homes and faculty and staff live on site with the students. The students are within walking distance of the host institution, QUT. Students are in class from 9AM-5PM each day. Over the past several years, the technical aspect of the class has focused on the use of unmanned vehicles for biological and ecological remote sensing. The goal of current research is to identify viable workflows and technologies that utilize unmanned aerial systems (UAS) for ecological science missions such as precision agriculture. During the initial planning stages the faculty-staff team wanted to ensure students had the opportunity to connect theory to practice; therefore, the program takes students through the entire span of the research process with infield experience. The project includes: a literature review, data collection, data processing, data analyzing, followed by presentation of results via an oral presentation to a scientific audience at the both the host and 
home university, and a research paper. Several of these projects have been published in as technical papers in pertinent STEM conferences and publications [12], [13].

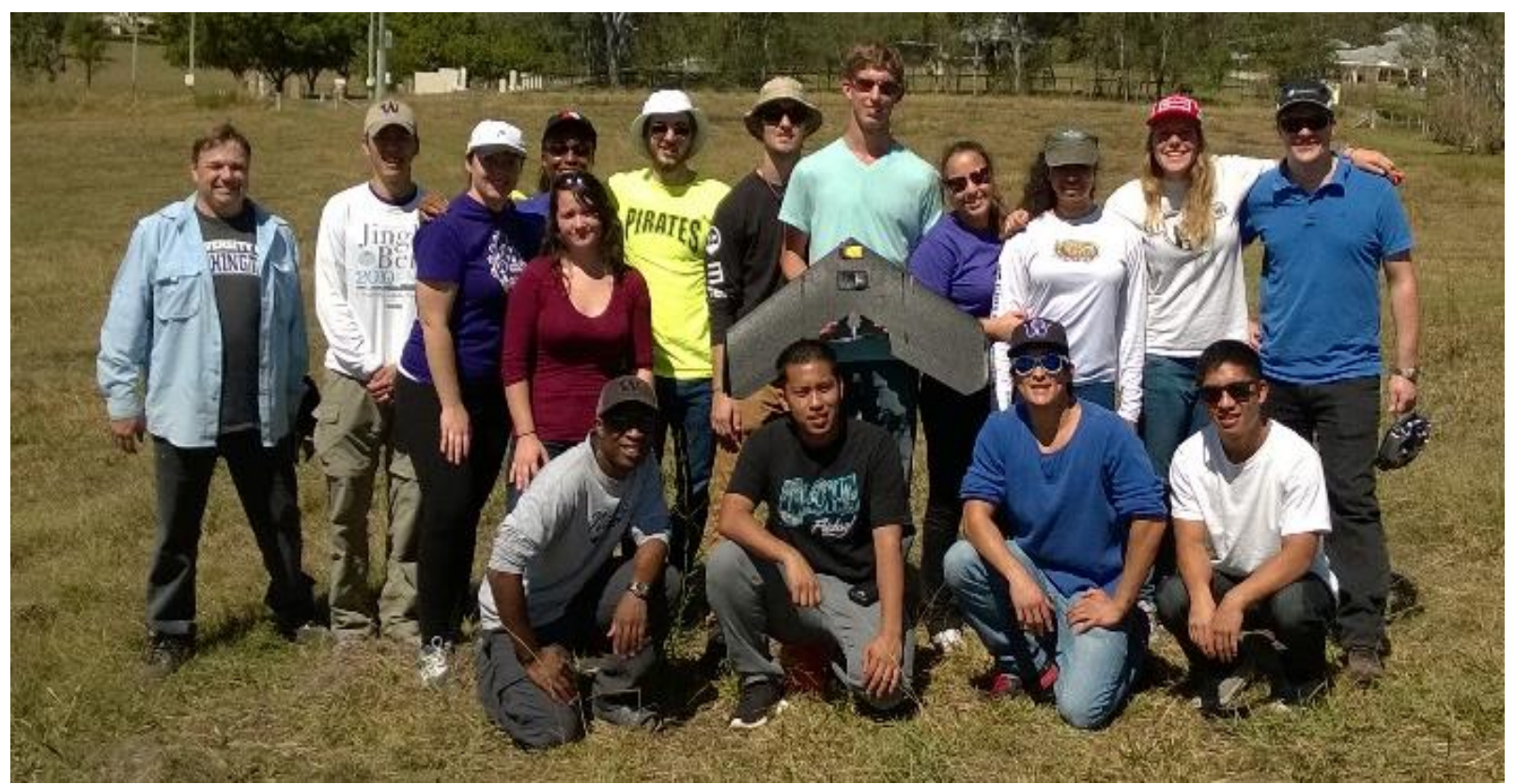

Figure 1: Students from the 2014 class gathering experimental data in the Australian Bush.

The course is built around a "co-teach" model. The faculty from the UW partner with faculty and graduate students from QUT for the length of the program.

The primary emphasis of the experience is on technical class content. As discussed previously the class has always focused on STEM technologies and content. More specifically, the class is mostly directed towards autonomous systems and remote sensing applications. For example, the 2014 class focused on developing an autonomous system to detect wildfires in the Australian coastal fringes and Outback using an unmanned aerial system (UAS) [12]. The subsequent class in 2015 expended on this idea and build custom UAS designed to obtain high-resolution imagery of an area using multi-spectral cameras [13]. Many of these topics are aligned with the faculty's own research programs [14], [15], [16], [17] thereby allowing students to continue these projects when the return to their home university by becoming involved as undergraduate researchers in the faculty's research groups or laboratories. 


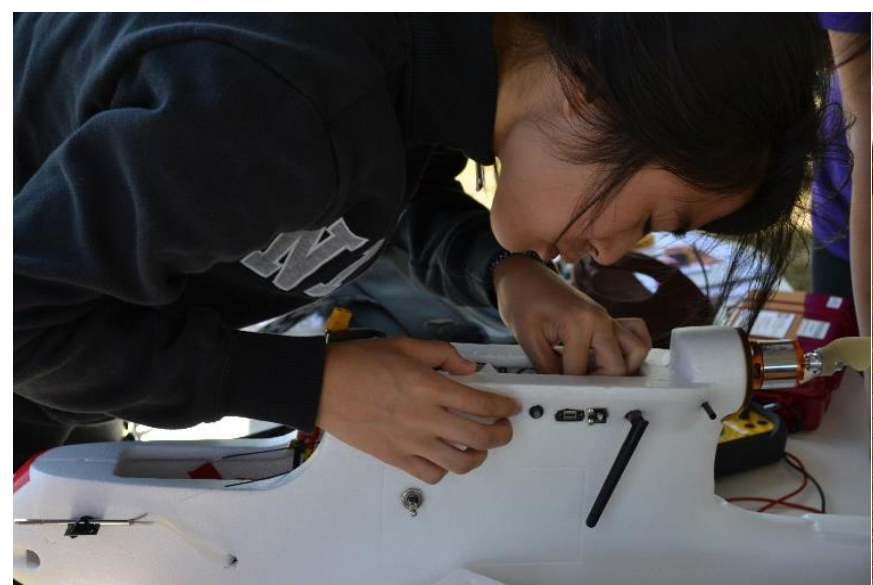

Figure 2: Students install avionics onto a UAS.

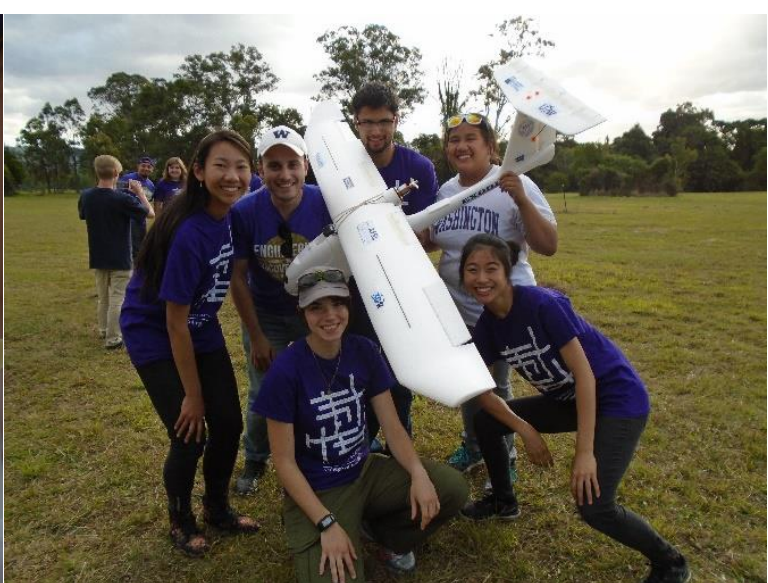

Figure 3: Students with a completed UAS ready to acquire remote data via a multispectral imager.

Research topics that the students undertake during this class is equivalent to a quarter long undergraduate research project. Students are expected to perform independent research and produce results that are of publication quality. This differs from traditional classes where the majority of the learning is doing through lectures and homework. In this class, students work as teams of researchers working towards a common goal. They follow a traditional research workflow starting from a problem thesis followed by a literature review and survey of the state of the art. Teams then form groups to work on relevant sections of the research project. For example, some students focus on developing the experimental apparatus (i.e. UAS or other robotic systems) while others perform simulation and mission planning. Following a successful laboratory test of the system, students conduct a scientific mission in the field to collect experimental data (Figure 4 and Figure 5). Faculty from both the host and home university assist in the execution of these field experiments, drawing on experience from previous research programs [18], [19], [20] to enable a smooth experience for the students. This data is then reduced and analyzed before being complied into an oral presentation and draft conference paper. Once the class ends, several of the students continue the research project which results in more significant results and peer reviewed technical publication over the course of the next academic school year [12], [13]. 


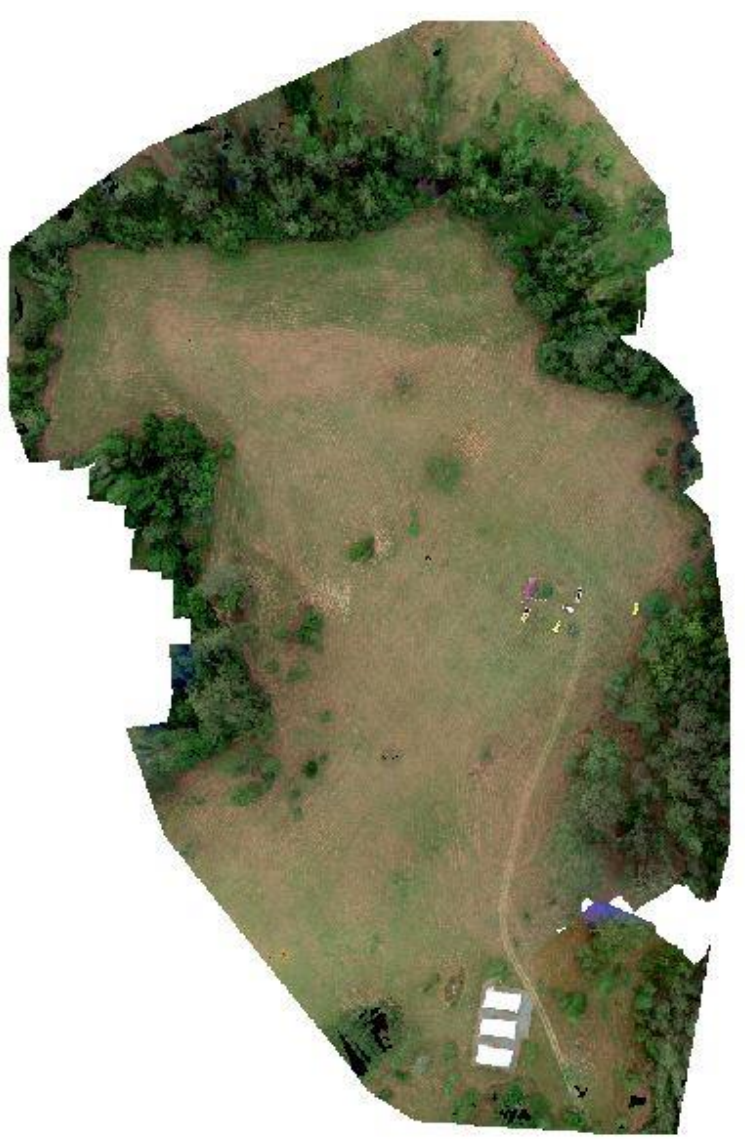

Figure 4: High resolution color mosaic image of a farm obtained from a UAS.

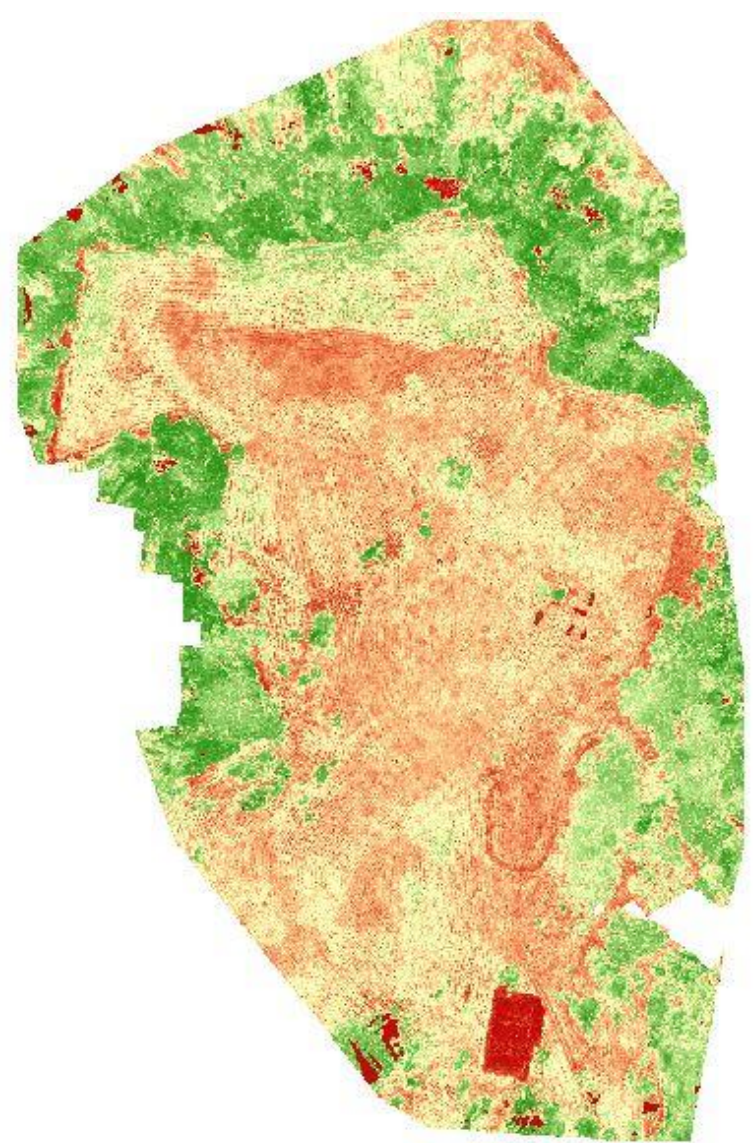

Figure 5: Resulting Normalized Difference Vegetation Index (NDVI) map of the same area

While primary emphasis is placed on technical class content, faculty and staff value the opportunity for students to engage in meaningful cross-cultural experiences with the local Australian community. This is particularly important for first time international travelers. While the program allows for student "free-time" there are a significant number of program-led cultural excursions that include but are not limited to: travel to the Great Barrier Reef, an aboriginal reserve, rugby game, high tea and local markets. In addition to class and cultural outings, one of the unique features of the program includes Australia STEM industry involvement as part of the curriculum. Industries such as Boeing Australia, and the Port of Brisbane, as well as the federal Commonwealth Scientific and Industrial Research Organisation (CSIRO) have been active participants with the program providing tours, demonstrations, and the opportunity for the students to speak with local engineers and scientists.

Throughout the duration of the program both the faculty and staff are supported by the UW Office of International Programs and Exchanges (IPE). IPE provides the team with two liaisons who assist with the budgetary aspects of the program as well as administrative functions.

program evaluation 
At the conclusion of the program there is an evaluation required by the university. The evaluation has a variety of scaled and opened questions. The inclusion of formative and summative program assessment assist program faculty and staff as they look to enhance and inform future programming. Program staff also meet to debrief program highlights and write a formal Director's report that is submitted to UW IPE. Key insights have been garnered through obtaining student voice including:

"I have never worked with software like MatLab and LaTex before so being exposed to it was a challenged that I found stimulating. Additionally, performing field experiments was an amazing experience" (UW Student)!

"Being entirely involved in the research process was a new experience for me and one that has helped me decide if this is a viable career pathway" (UW Student).

"The modeling and imaging techniques described in this class has given me inspiration and insight for new projects" (UW Student).

"Very different from any course I have taken. Integrating research and industry all in one was very interesting experience and great in order to develop a perspective on research outside of the U.S." (UW Student)

After five years of programming the faculty and staff are looking to undertake a closer analysis of program impact. Part of these efforts will include focus groups with past participants, and indepth 1:1 interviews. Currently demographic and descriptive statistics capture participation by enrollment status, colleges represented, major status at the time of graduation, gender, and race/ethnicity are shown in the following figures.

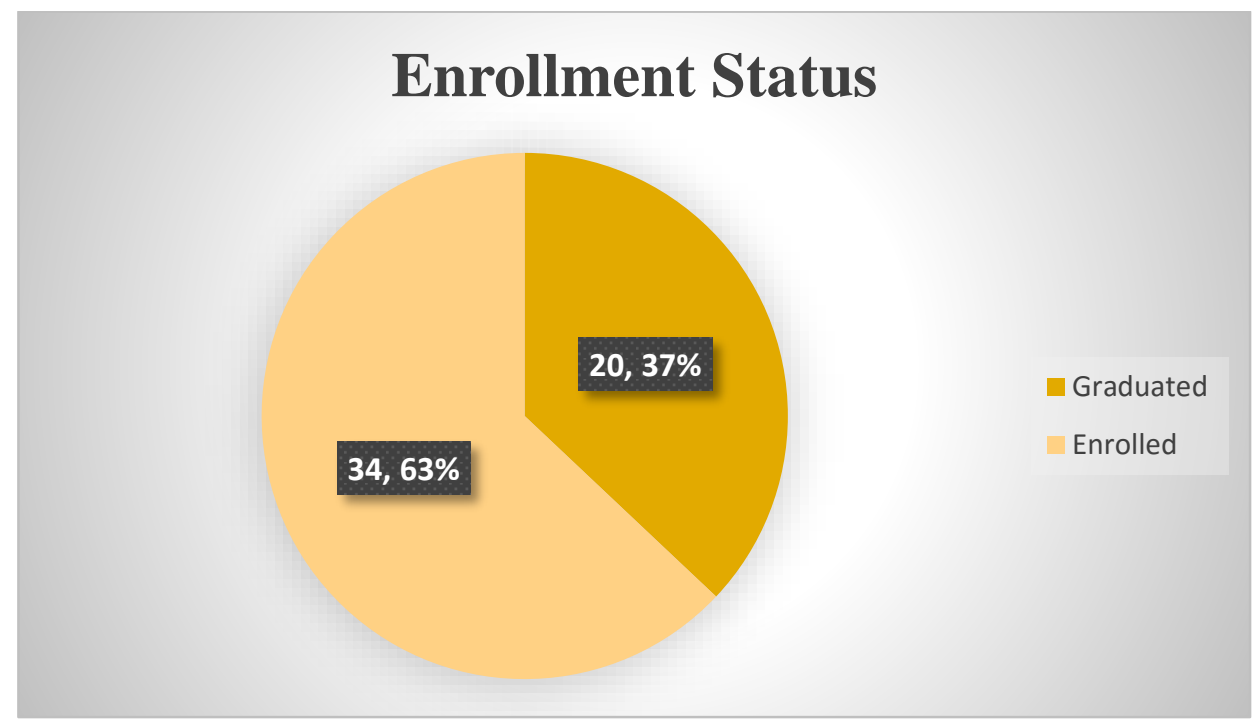

Figure 6: Enrollment status for cohorts 2012 - 2015 


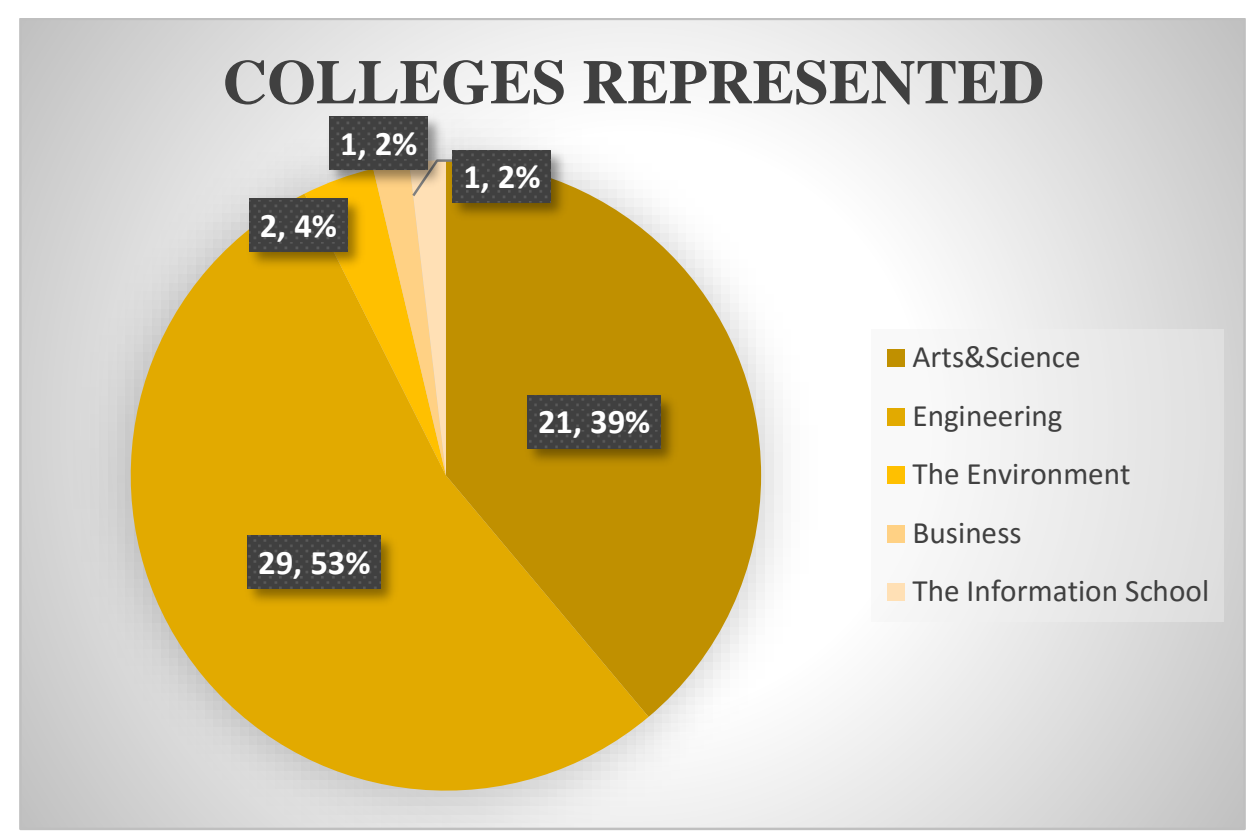

Figure 7: Colleges represented in cohorts 2012 - 2015

\section{Major at Time of Application}

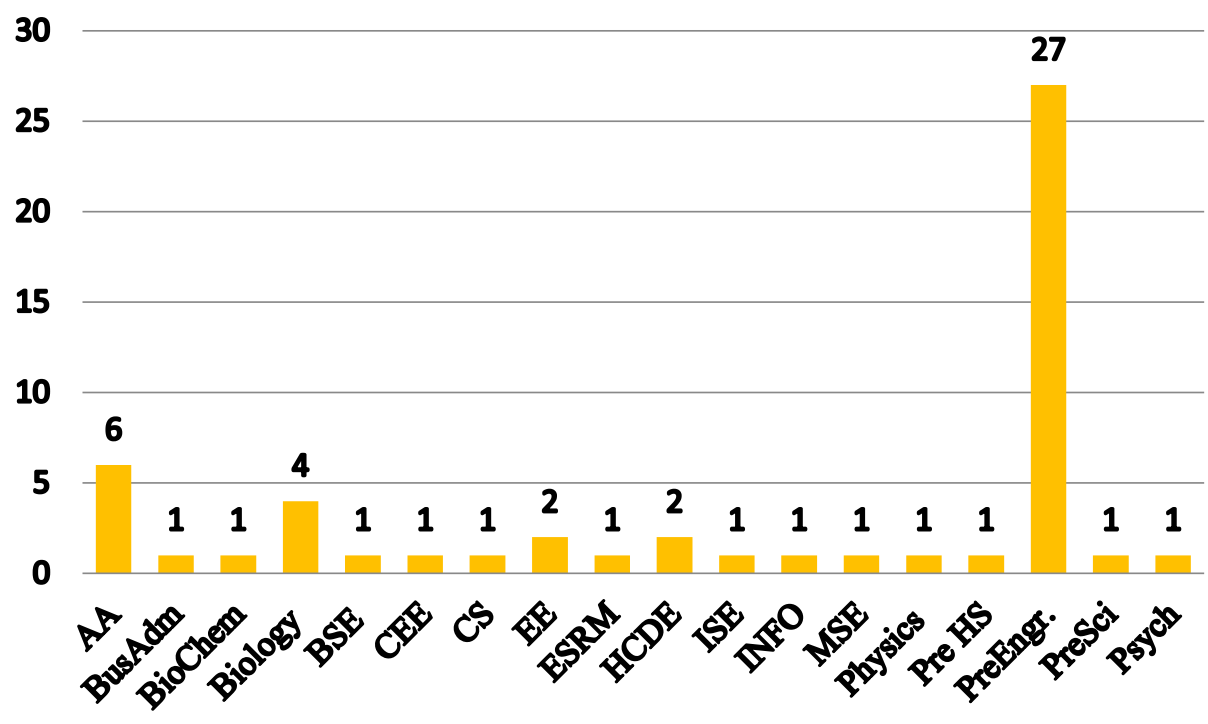

Figure 8: Major status at time of application for cohorts 2012 - 2015 


\section{Gender}

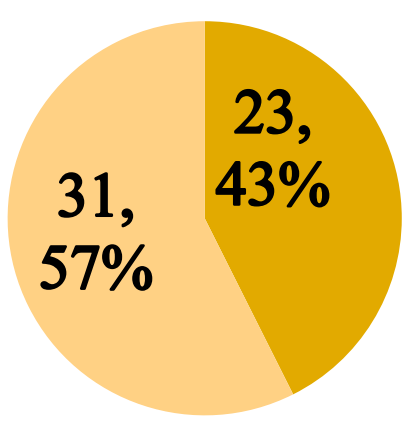

Female

Male

Figure 9:Gender distribution of for cohorts 2012 - 2015

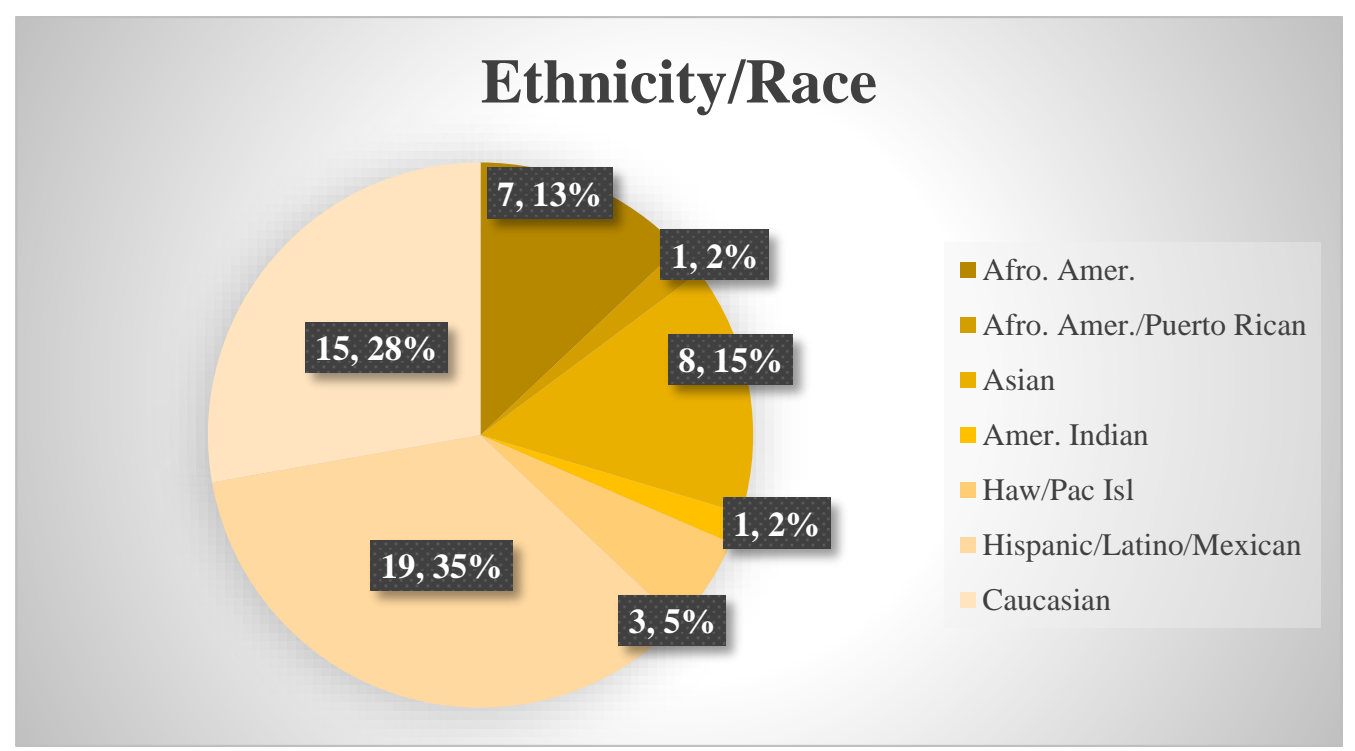

Figure 10: Ethnicity/racial distributions for cohorts 2012 - 2015.

risks and challenges

While the UW IPE Office provides support and structure for the program there are still a number of potential and or actualized risks and challenges associated with the program. The primary risks and challenges associated with the Brisbane, Australia study abroad include 1) student behavior and conduct; 2) recruitment of diverse students; 3) cost; 4) logistics in an international context and 5) differing cultural norms and identity politics.

Student behavior and conduct is a paramount concern for faculty and staff leading international initiatives. For many students travel abroad is an exciting time to free oneself from constraints and explore new surroundings. While these experiences are encouraged there is always the risk 
that behavior may "push the boundaries" putting participants and the program at risk. In Australia, one of the salient concerns is the drinking age (18) which is lower than that in the U.S. Students under 21 may have a strong desire or may be influenced by older peers to engage in behaviors and experiences that are not part of their routine in their home country. To minimize risk, program staff work with the IPE office to provide mandatory pre-departure alcohol training, students are also oriented to program expectations once they are in the visiting country. One of the benefits of having a program where students are recruited from the Diversity and Access (WiSE and MSEP) and LSAMP programs is that the staff have prior knowledge of applicants and can vouch for students' temperaments thereby lowering the risk for potential behavioral problems and a placing sense of higher accountability and expectations on the shoulders of the students. In addition, many of the students have had previous engagement with one another and this has assisted in promoting a safe and familiar community that enhances the learning environment.

Recruitment of diverse students has been a challenge for the program. Historically groups from low-socioeconomic, first generation and or minority backgrounds have not participated in study abroad as their more affluent peers [4], [5]. Faculty and staff have to work year round to identify and engage with students who may be of the aforementioned backgrounds. Many times fears, finances and family dynamics have to be negotiated for the student to feel comfortable and able to participate in the program. Fears and/or reservations for traveling abroad have been raised more around location of programs than traveling in general. Questions such as "is there a current political standing or sense of distress that may bring harm to U.S. citizens?" may influence decisions. Family dynamics tend to come into play with the students sharing that family hesitations and concerns come with understanding the overall value of studying abroad for the STEM major. For example, "will this help the student get into their major?", "will this interfere with graduating in four years?", or "how will this help them obtain a job?" are a few of the concerns parents will bring into the equation. The staff share research and data during the recruitment process to educate the students on the benefits of learning abroad to their academic, professional and personal development. To reduce conflict with a students preferred graduation time, the program is delivered in the latter part of the summer. Students are still able to take a course during the summer quarter, pursue an internship or job to help with expenses, and even participate in undergraduate research. It is highly suggested that they meet with their department advisors to confirm the credit earned can be applied to fulfill their major engineering or science elective requirement. We encourage them to share this same information with their family.

Cost also has major implications for the targeted program participants and their ability to participate in the program. The family concern raised here is integrating this cost into the bigger equation of affording college in general. The Australia program has fees of up to a $\$ 5500$ not including the airfare that ranges from \$1700 to \$2000 U.S. dollars, thus students from lowsocioeconomic backgrounds need support to ensure they are able to participate. Program staff leverage their networks to secure scholarships, fundraise, and secure departmental and or college resources to help those students most in need. In addition, if available to them, students have the option of utilizing portion of their financial aid. 
Logistics in an international context can be fluid and ever changing, thus it is important when developing and leading a study abroad excursion that faculty and staff are flexible in their approach to the work. While previous working relationships with QUT faculty and industry partners provided some assistance navigating details in Brisbane, there were still various challenges relative to the day-to-day operations. Planning for the program is a yearly process, and contract negotiation with vendors occurs throughout the spring and summer quarters. While program faculty and staff work in advance to plan detailed excursions and class projects, there were multiple incidences that required on the ground modifications to the syllabus and agenda. Basic infrastructure and services that are available in the U.S. are sometimes difficult to access in other parts of the world. For example the internet connection in Australia was not as expansive and operational and required the faculty and staff team to adapt onsite to accommodate participants.

Differing cultural norms and identity politics were a consideration for the faculty and staff leading the Brisbane program. Because of historical racism and oppression faced by particular racial and ethnic groups in the U.S., the consideration of "isms" (e.g. racism) in Australia was a concern. There was also consideration for the multiple dimensions of identity including nationalism or "American" identity and what that symbolized abroad. Many of the program participants were from historically underrepresented backgrounds thus the faculty and staff talked openly about the historical context of the continent of Australia with specific focus on the native Aboriginal people and European colonists. To help inform participant knowledge relative to Australia's history, faculty and staff had students research the history of the continent prior to their departure and share with the larger group. There were also parallels that were drawn for students relative to the Native American experience in the U.S. and the aboriginal people in Australia as a way to better prepare participants for some of the dynamics they may encounter upon arrival. Finally, once in Brisbane participants visited a "reserve" which is similar to a reservation in the U.S. Participants were able to meet with aboriginal elders to hear about their struggles and oppression and the movement to reclaim their land, recognition as the original people, and healing process.

outcomes and future implications

Academic year 2015-16 marks the fifth year of the Brisbane, Australia program. Over a five year period the program has experienced a number of successes and has realized expansion and growth through continued partnerships and a growing international network. When the program was initially developed the primary focus was to bring diverse UW STEM students from the U.S. to the QUT Brisbane campus. Through continued dialogue with UW and QUT faculty/staff, as well as a generous grant from the UW Office of Global Affairs, the program was able to develop and expand the parameters of the program to include reciprocal research opportunities for 2-3 students from QUT at UW. These students traveled to UW during the 2015 - 2016 academic year to engage in research internships with the faculty director's research lab. The results of these interactions is another technical conference publication with the undergraduate students involved in the study abroad program and the QUT students as joint authors [13]. 
Additional outcomes have included the opportunity to present at national conferences [21] and share information with colleagues on developing programs and recruitment of diverse students in the STEM fields [22].

\section{Bibliography}

[1] J. Simon and J. W. Ainsworth, "Race and socioeconomic status differences in study abroad participation: The role of habitus, social networks, and cultural capital," ISRN Education, vol. 2012, 2012.

[2] D. Fusch, "Minority Students: Study Abroad and Academic Success," Academic Impressions, 24 February 2011. [Online]. Available: http://www.academicimpressions.com/news/minority-students-study-abroad-andacademic-success. [Accessed 31 January 2016].

[3] A. George, "Opinion: Minorities are underrepresented in study abroad programs," The Maron, 24 April 2015. [Online]. Available: http://www.loyolamaroon.com/10003914/oped/minorities-are-underrepresented-in-studyabroad-programs/. [Accessed 31 January 2016].

[4] Institute of International Education, "Open Doors Report on International Educational Exchange," Institute of International Education, 2015.

[5] Institute of International Education, "Open Doors," Institute of International Education, 16 November 2015. [Online]. Available: http://www.iie.org/Research-and-Publications/Open-Doors. [Accessed 31 January 2016].

[6] M. H. Salisbury, P. D. Umbach, M. B. Paulsen and E. T. Pascarella, "Going global: Understanding the Choice Process of the Intent to Study Abroad," Research in Higher Education, vol. 50, no. 2, pp. 119-143, 2009.

[7] D. Sand, "New efforts to boost minority students studying abroad," USA Today, 23 October 2013.

[8] E. Redden, "Study Abroad Isn't Just for White Students," Inside Higher Ed, 11 June 2007. [Online]. Available: https://www.insidehighered.com/news/2007/06/11/diversity. [Accessed 31 January 2016].

[9] B. Tensley, "What's Keeping Black Students From Studying Abroad?," The Atlantic, 13 March 2015.

[10] C. E. McLellan, "A Lesson Plan to Improve Minority Study Abroad Participation," Diverse: Issues in Higher Learning, 1 November 2007. [Online]. Available: http://diverseeducation.com/article/9988/. [Accessed 31 January 2016].

[11] C. M. Steele, "Thin Ice: Stereotype Threat and Black College Students," [Online]. Available: http://www.theatlantic.com/magazine/archive/1999/08/thin-ice-stereotype-threat-and-black-collegestudents/304663/. [Accessed 21 March 2016].

[12] C. W. Lum, A. Summers, B. Carpenter, A. Rodriguez and M. Dunbabin, "Automatic Wildfire Detection and Simulation Using Optical Information from Unmanned Aerial Systems," in Proceedings of the 2015 SAE Aerotec Conference, Seattle, 2015.

[13] C. W. Lum, M. MacKenzie, C. Shaw-Feather, E. Luker and M. Dunbabin, "Multispectral Imaging and Elevation Mapping from an Unmanned Aerial System for Precision Agriculture Applications," in Proceedings of the 13th International Conference on Precision Agriculture, 2016.

[14] C. W. Lum, J. Vagners and R. T. Rysdyk, "Search Algorithms for Teams of Heterogeneous Agents with Coverage Guarantees," AIAA Journal of Aerospace Computing, Information, and Communication, vol. 7, no. 1, pp. 1-31, 2010.

[15] C. W. Lum and B. Waggoner, "A Risk Based Paradigm and Model for Unmanned Aerial Systems in the National Airspace," in Proceedings of the AIAA Infotech@Aerospace Conference, St. Louis, 2011. 
[16] C. W. Lum and J. Vagners, "A Modular Algorithm for Exhaustive Map Searching Using Occupancy Based Maps," in Proceedings of the AIAA Infotech@Aerospace Conference, Seattle, 2009.

[17] K. Ueunten, C. W. Lum, A. A. Creigh and K. Tsujita, "Conservative Algorithms for Automated Collision Awareness for Multiple Unmanned Aerial Systems," in Proceedings of the IEEE Aerospace Conference, Big Sky, 2015.

[18] C. W. Lum, J. Vagners, J.-S. Jang and J. Vian, "Partioned Searching and Deconfliction: Analysis and Flight Tests," in Proceedings of the IEEE American Control Conference, Seattle, 2010.

[19] C. W. Lum, J. Vagners, M. Vavrina and J. Vian, "Formation Flight of Swarms of Autonomous Vehicles In Obstructed Environments Using Vector Field Navigation," in Proceedings of the International Conference on Unmanned Aircraft Systems, 2012.

[20] M. Dunbabin and L. Marques, "Robots for Environmental Monitoring: Significant Advancements and Applications," Robotics \& Automation Magazine, vol. 19, no. 1, pp. 24-39, 2012.

[21] K. Ceniceros, S. Gardner and C. Jordan, "Moving Beyond Barriers: Transforming International Education Through Inclusive Excellence," Diversity Abroad Conference, New Orleans, 2015.

[22] S. Gardner and C. Jordan, "A Call to Action LSAMP Model for Broadening Participation in STEM," LSAMP National Conference, Indianapolis, 2015. 